\title{
Periostitis in a Patient with Inflammatory Bowel Disease
}

FLORIAN BAILLY, MD, AP-HP, Hôpital Lariboisière, Pôle Appareil Locomoteur, Fédération de Rhumatologie, Universite Paris Diderot; DAVID PETROVER, MD, AP-HP, Hôpital Lariboisière, Pôle Appareil Locomoteur, Service de Radiologie Ostéo-Articulaire, Universite Paris Diderot; MATTHIEU ALLEZ, MD, PhD, AP-HP, Hôpital Saint Louis, Service d'Hépato-Gastro-Entérologie; PASCAL RICHETTE, MD, PhD, Hôpital Lariboisière, Pôle Appareil Locomoteur, Fédération de Rhumatologie, Universite Paris Diderot, Paris, France. Address correspondence to Dr. P. Richette, Fédération de Rhumatologie, Hôpital Lariboisière, 2 Rue Ambroise Paré, 75475 Paris cedex 10, France. E-mail: pascal.richette@1rb.aphp.fr. J Rheumatol 2012;39:2179-80; doi:10.3899/jrheum.120672

Periostitis has been associated with a variety of diseases, and can occur alone or with clubbing and arthritis. Acute periostitis is due to infection, and is characterized by diffuse suppuration, severe pain, and constitutional symptoms.

An 18-year-old man was referred for evaluation of recent and sharp pain in both inner thighs. Four months previously, he had undergone proctocolectomy with ileal pouch-anal anastomosis for severe refractory ulcerative colitis. The pain began during a 2-week episode of acute pouchitis, treated with antibiotics. Clinical examination revealed neither enthesitis nor synovitis in lower limbs, but intense pain on palpation of both femurs.

Radiographs of the femurs showed a solid periosteal reaction along the diaphysis (Figure 1A, arrow). Magnetic resonance imaging revealed extensive periostitis characterized by increased short-tau inversion recovery signal inten-

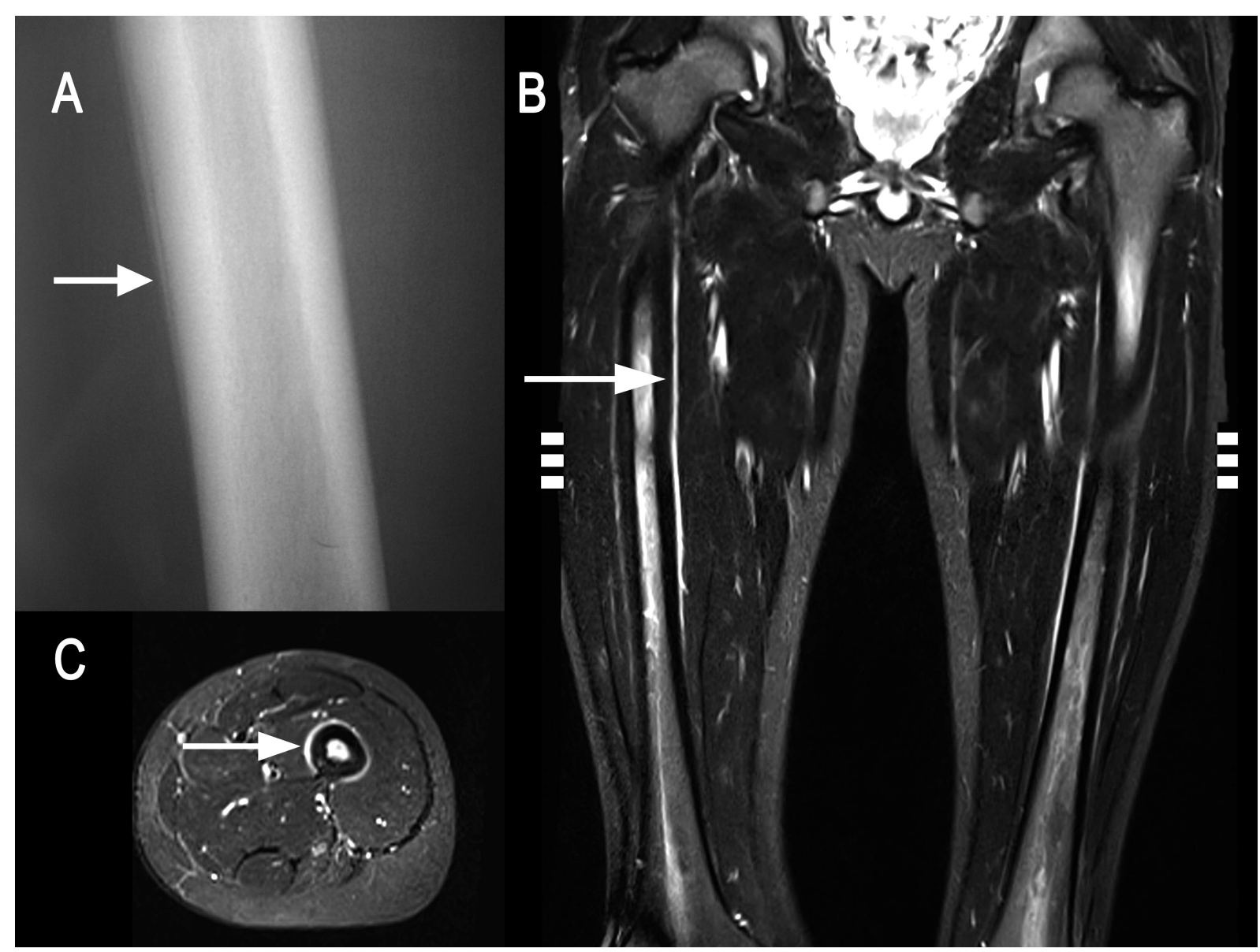

Figure 1. A. Radiograph of the femur shows a solid periosteal reaction (arrow) along the diaphysis. B. Magnetic resonance imaging (MRI) indicates extensive periostitis in both femurs (arrow). C. MRI shows high signal intensity on axial gadolinium-enhanced fat-suppressed T1-weighted images (arrow). 
sity of the periosteum of both femurs (Figure 1B, arrow) and a circumferential high signal intensity on axial gadolinium-enhanced fat-suppressed T1-weighted images (Figure $1 \mathrm{C}$, arrow).

Musculoskeletal complications are frequent manifestations of inflammatory bowel diseases (IBD), which are in most cases spondyloarthritis, with peripheral and axial involvement. Periostitis is also a rare but well recognized complication of IBD.

Periostitis can be found alone or can be associated with clubbing and arthritis that define hypertrophic osteoarthropathy $(\mathrm{HOA})^{1}$. Periostitis (with or without HOA) has been reported in association with a variety of diseases, mainly pulmonary malignancies but also with chronic infections, cyanotic congenital heart diseases, and various liver conditions, as well as IBD ${ }^{2}$. Several case studies ${ }^{3}$ have reported that pamidronate might alleviate pain and other HOA-related symptoms. In our case, the patient received analgesics, and the pain gradually resolved.

\section{REFERENCES}

1. Segal AM, Mackenzie AH. Hypertrophic osteoarthropathy: A 10-year retrospective analysis. Semin Arthritis Rheum 1982;12:220-32.

2. Yao Q, Altman RD, Brahn E. Periostitis and hypertrophic pulmonary osteoarthropathy: Report of 2 cases and review of the literature. Semin Arthritis Rheum 2009;38:458-66.

3. Jayakar BA, Abelson AG, Yao Q. Treatment of hypertrophic osteoarthropathy with zoledronic acid: Case report and review of the literature. Semin Arthritis Rheum 2011;41:291-6. 